Technological University Dublin ARROW@TU Dublin

\title{
Activity monitoring in professional soccer goalkeepers during training and match play
}

\author{
Victor Moreno-Pérez \\ Universidad Miguel Hernandez de Elche, vmoreno@goumh.es \\ Shane Malone \\ Technological University Dublin, Shane.Malone@TUDublin.ie \\ Lluís Sala-Pérez \\ Universitat de Girona
}

See next page for additional authors

Follow this and additional works at: https://arrow.tudublin.ie/ittsciart

Part of the Sports Sciences Commons

\section{Recommended Citation}

Victor Moreno-Pérez, Shane Malone, Lluís Sala-Pérez, Manuel LapuenteSagarra, Miguel Angel CamposVazquez \& Juan Del Coso (2019): Activity monitoring in professional soccer goalkeepers during training and match play, International Journal of Performance Analysis in Sport, DOI: 10.1080/

24748668.2019.1699386

This Article is brought to you for free and open access by the School of Science and Computing at ARROW@TU Dublin. It has been accepted for inclusion in Articles by an authorized administrator of ARROW@TU Dublin. For more information, please contact arrow.admin@tudublin.ie, aisling.coyne@tudublin.ie, gerard.connolly@tudublin.ie.

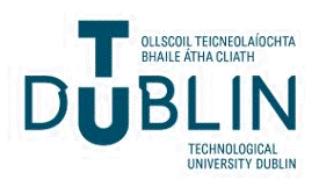




\section{Authors}

Victor Moreno-Pérez, Shane Malone, Lluís Sala-Pérez, Manuel Lapuente-Sagarra, Miguel Angel CamposVazquez, and Juan Del Coso 
See discussions, stats, and author profiles for this publication at: https://www.researchgate.net/publication/337696059

\section{Activity monitoring in professional soccer goalkeepers during training and match play}

Article in International Journal of Performance Analysis in Sport · December 2019

DOl: 10.1080/24748668.2019.1699386

CITATIONS

6 authors, including:

2. Victor Moreno Perez

Universidad Miguel Hernández de Elche

75 PUBLICATIONS 431 CITATIONS

SEE PROFILE

2. Lluis Sala-Perez

Polish National Football Association

2 PUBLICATIONS 22 CITATIONS

SEE PROFILE

Some of the authors of this publication are also working on these related projects:
481

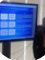

Shane Malone

Technological University Dublin - Tallaght Campus

65 PUBLICATIONS 1,478 CITATIONS

SEE PROFILE

Manuel Lapuente-Sagarra

Universidad del País Vasco / Euskal Herriko Unibertsitatea 6 PUBLICATIONS 24 CITATIONS

SEE PROFILE

Measure the correlation between biological age and chronological age with specific tests in soccer (sports science) View project

Phd Project View project 
See discussions, stats, and author profiles for this publication at: https://www.researchgate.net/publication/337696059

\section{Activity monitoring in professional soccer goalkeepers during training and match play}

Article · December 2019

DOI: $10.1080 / 24748668.2019 .1699386$

\section{CITATIONS}

6 authors, including:

29

Victor Moreno Perez

Universidad Miguel Hernández de Elche

34 PUBLICATIONS 112 CITATIONS

SEE PROFILE

2. Lluis Sala-Perez

FC Girondins de Bordeaux

2 PUBLICATIONS 5 CITATIONS

SEE PROFILE
READS

59

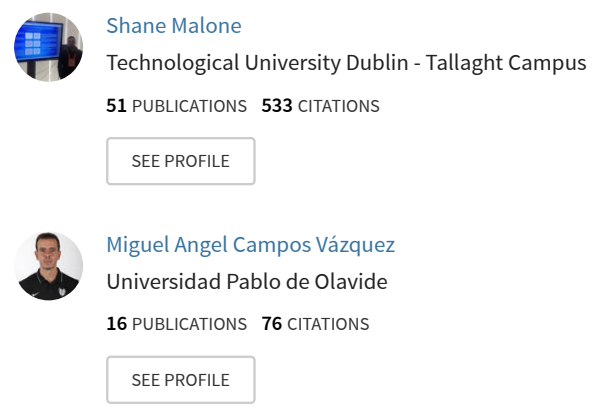

Some of the authors of this publication are also working on these related projects:

"Evaluation of the acute responses and exercise-induced muscle damage of playing consecutive badminton matches in a day or accumulated matches during several days". View project

The physical and physiological demands of elite international female field hockey players View project 


\section{International Journal of Performance Analysis in Sport}

\section{Activity monitoring in professional soccer goalkeepers during training and match play}

Victor Moreno-Pérez, Shane Malone, Lluís Sala-Pérez, Manuel LapuenteSagarra, Miguel Angel Campos-Vazquez \& Juan Del Coso

To cite this article: Victor Moreno-Pérez, Shane Malone, Lluís Sala-Pérez, Manuel LapuenteSagarra, Miguel Angel Campos-Vazquez \& Juan Del Coso (2019): Activity monitoring in professional soccer goalkeepers during training and match play, International Journal of Performance Analysis in Sport, DOI: 10.1080/24748668.2019.1699386

To link to this article: https://doi.org/10.1080/24748668.2019.1699386

册 Published online: 02 Dec 2019.

Submit your article to this journal 지

Q View related articles $\longleftarrow$

View Crossmark data $\nearrow$ 


\title{
Activity monitoring in professional soccer goalkeepers during training and match play
}

\author{
Victor Moreno-Pérez (iD) ${ }^{a}$, Shane Malone ${ }^{\mathrm{b}, \mathrm{c}}$, Lluís Sala-Pérez ${ }^{\mathrm{d}, \mathrm{e}}$, Manuel Lapuente- \\ Sagarra ${ }^{f}$, Miguel Angel Campos-Vazquez ${ }^{\mathrm{g}}$ and Juan Del Coso ${ }^{\mathrm{h}}$
}

a Sports Research Centre, Miguel Hernandez University of Elche, Alicante, Spain; ${ }^{b}$ Human Performance Lab, Technological University Dublin, Tallaght, Ireland; 'The Tom Reilly Building, Research Institute for Sport and Exercise Sciences, Liverpool John Moores University, Liverpool, UK; dSport Science Department, FC Girondins of Bordeaux, Bordeaux, France; eUniversity School of Health and Sport (EUSES), University of Girona, Girona, Spain; ${ }^{f}$ Analysis \& Scientific Support Unit of Royal Spanish Track and Field Federation, Spain; 9 Faculty of Sports, Pablo de Olavide University, Sevilla, Spain; ${ }^{h}$ Centre for Sport Studies, Rey Juan Carlos University, Alcorcón, Spain

\begin{abstract}
The purpose of the present study was to quantify the external load of professional soccer goalkeepers. Twenty professional goalkeepers participated in the study. Data were classified according to the number of days before or after the match day (MD) as follows: MD-4, MD-3, MD-2, MD-1 for the sessions before the match, and MD+1 for the session after the match. The total running distance covered (TD), the high metabolic load (HMLD), the number of high metabolic load efforts (HMLE) were progressively reduced from MD-4 to MD-1 but the values of these variables were always inferior to $M D$ (ES: -3.79 to -1.11$)$. There was a tendency for a progressive reduction in the number of high-intensity accelerations (ACC) and decelerations (DEC) from MD-4 to MD-1 although the values of ACC/DEC were superior to MD (ES: 0.19 to 2.05). Overall, MD-2 was the day with the lowest external load. During training sessions, starter goalkeepers performed more TD (ES: 0.36) and more HMLE (ES: 0.29) than non-starters. External load was progressively decreased in the days before match play for goalkeepers which is reflective of appropriate recovery and preparation practices within the cohort analysed. However, habitual goalkeepers training has an excess of accelerations/decelerations and a lack of running actions performed at high metabolic loads.
\end{abstract}

\section{ARTICLE HISTORY}

Received 3 November 2019

Accepted 27 November 2019

\section{KEYWORDS}

Football; muscle performance; match demands; team-sport; soccer player

\section{Introduction}

During soccer match-play, the role of the soccer goalkeeper is not akin to that of other outfield playing positions. As such, the position is often overlooked from an external loading perspective at the elite level and within research (Malone, Jaspers, et al., 2018; White et al., 2018). The role of soccer goalkeepers is such that the position has a central impact on the final match outcome because they perform individual actions that can prevent the opposing team from scoring (Seaton \& Campos, 2011). On the other hand, a single mistake made by a soccer goalkeeper can end in a goal of the opposing team which

CONTACT Victor Moreno-Pérez vmoreno@goumh.es 0 Sports Research Centre, Miguel Hernandez University of Elche, Avda. de la Universidad s/n., P.C. 03202, Elche (Alicante), Spain 
represents a unique responsibility for goalkeepers during match play when contrast to other positions of play (Liu, Gómez, \& Lago-Peñas, 2015; Seaton \& Campos, 2011). The position of goalkeeper can be said to constitute the most specialised role during soccer play with their actions typically demanding high-velocity kicking, jumping, throwing, and a combination of other specific explosive and short duration movements such as diving, catching, accelerating, and decelerating sharply (Russell, Rees, Benton, \& Kingsley, 2011; Ziv \& Lidor, 2011). Although most of the actions of the soccer goalkeeper are performed within the penalty area, it has been found that their actions have an impact the movements of the opposing team' players and decisions an example of this is during penalty scenarios (Lopes, Araújo, Duarte, Davids, \& Fernandes, 2012). During the past decade, several investigations have focussed on determining the external physical demands of soccer match-play with respect to positional lines (Bangsbo, Mohr, \& Krustrup, 2006; Mohr, Krustrup, \& Bangsbo, 2003). These studies have observed that outfield players cover an average distance of 10-12 km (Krustrup et al., 2009; Weston, Castagna, Helsen, \& Impellizzeri, 2009), and perform about 40 sprints per match (Barberó-Álvarez, Boullosa, Nakamura, Andrín, \& Weston, 2014). In contrast, soccer goalkeepers cover an average of 4-6 km in a competition match while they perform only two sprint actions (Di Salvo, Benito, Calderón, Di Salvo, \& Pigozzi, 2008; Malone, Jaspers, et al., 2018). However, these previous investigations have overlooked the short and intense actions of goalkeepers that are habitually performed without changes in the position. Therefore, the physical qualities of goalkeepers are significantly different to those of outfield players. As such, for goalkeepers to adequately prepare for competition, they must engage in position-specific training that replicates match-play movements during specific acute and chronic phases (Malone, Jaspers, et al., 2018), not only because of the restriction in the field area that they cover, but also because they utilise mainly the upper body for in-game actions within the goal area.

In soccer, the identification of the external movement demands during the match is important to adequately tailor training towards the competitive profile of specific positions of play (Brink, Nederhof, Visscher, Schmikli, \& Lemmink, 2010). Appropriate training planning based on match demands enables players to perform all actions of the game with the greatest efficiency and effectiveness (Iaia, Rampinini, \& Bangsbo, 2009). In addition, although it is known that general and position-specific preparation is important, practitioners have to strike a fine balance between the optimal loading players and elevating injury risk (Drew \& Finch, 2016; Gabbett et al., 2016; Gabbett \& Whiteley, 2017). To the best of our knowledge, few studies have tried to quantify the external load placed on soccer goalkeepers. Therefore, coaches have restricted knowledge as to the external load being place on their players and reduced applicable data available to maximise goalkeepers conditioning practices.

The most commonly reported external load variable within the literature with respect to goalkeepers is distance covered, in absolute values and across different speed thresholds (Di Salvo et al., 2008; White et al., 2018). Previously, Di Salvo et al. (2008) analysed the distance covered at different speed thresholds across 62 goalkeepers. The authors observed that goalkeepers covered $\sim 5.6 \mathrm{~km}$ while $1 \%$ of this distance was completed at high-speed with only $0.2 \%$ completed above sprint thresholds. However, speed and distance-based analysis neglects the frequent occurrence of sudden transitions between low and high exercise intensities (Osgnach, Poser, Bernardini, Rinaldo, \& Di Prampero, 
2010). In addition, the load imposed by high-intensity movements that are performed with minimal changes of position (saves, clearances, slide-tackles, etc.) are habitually underestimated. Metabolic power (MP) is a relatively new proposal to measure exercise intensity and represents an approach to estimate the energetic demands of intermittent locomotion typically seen in team sports (Polglaze \& Hoppe, 2019). MP is proposed as a more accurate way of calculating exercise intensity in team sport players because it integrates both the speed and acceleration that the player demonstrates at each moment, instead of considering them separately (Osgnachsgnach et al., 2010). However, MP presents some limitations to assess certain physiologically demanding actions such as high-velocity kicking, jumping, throwing and diving, that are likely to increase the overall physical load experienced by goalkeepers (Russell et al., 2011).

To the date, only one recent study has quantified the external load of goalkeepers during training sessions and matches by using a complex analysis that includes distances, speed of movement, accelerations and decelerations (Malone, Jaspers, et al., 2018). However, this analysis only examined one goalkeeper for a complete season; therefore, it is difficult to extrapolate previous findings to a more generalised context. Therefore, the aim of the current study was to quantify the external load of professional soccer goalkeepers during training and match play through the utilisation of global positioning system (GPS) technology.

\section{Methods}

\subsection{Subjects}

In this prospective observational study, $20(n=20)$ professional soccer goalkeepers (age, 27.6 \pm 2.0 years; body mass, $81.8 \pm 0.8 \mathrm{~kg}$; height, $186.3 \pm 0.2 \mathrm{~cm}$ ) volunteered to participate in this investigation. All goalkeepers played in the second division of the Spanish football league (BBVA League). The goalkeepers were divided into two groups depending on their role during the match competition: 1 ) Starting goalkeepers ( $n=10$, age: $29 \pm 4.8$ years; body mass: $80.8 \pm 3.9 \mathrm{~kg}$; height: $186.2 \pm 3.4 \mathrm{~cm})$ and 2$)$ Non-starting goalkeepers ( $n=10$, age: $26.1 \pm 4.2$ years; body mass: $81.8 \pm 3.6 \mathrm{~kg}$; height: $186.4 \pm 4.1 \mathrm{~cm}$ ). The inclusion criteria for the current study included: a) To be male professional goalkeeper, b) to have the capacity of train without any physical restriction c) to be injury free. The following criteria were considered as grounds for exclusion from the current investigation: a) history of pain or any kind of injury during the observation period; b) non completion of regular training during the observation period. Prior to the observational period and post ethical approval by the Miguel Hernandez University Ethics Committee (2018.65.E.OIR), participants attended to an information talk where they were briefed about the purpose, benefits, and procedures of the study. Written informed consent and medical declaration were obtained from participants while the study fulfilled all procedures set in the newest version of the Declaration of Helsinki.

\subsection{Data collection}

Goalkeepers' external training load data were collected from two competitive matches and two consecutive training weeks during January of 2017-2018 season. Data were analysed in relation to the typical soccer training load analysis scheme of the number of 
days pre or post-match day (match day plus or minus method; $\mathrm{MD} \pm$ ), in line with previously published literature (Malone, Jaspers, et al., 2018). Within this training load analysis method all training sessions 4 days prior to match-play were coded as MD-4, all training sessions 3 days prior to match-play were coded as MD-3, all training sessions 2 days prior to match-play were coded as MD-2, all training sessions 1 day prior to matchplay were coded as MD-1, with all training sessions 1 day after match-play coded as MD +1 . Although the non-starter goalkeepers never participated during match-play, the training load $(\mathrm{MD} \pm)$ of their team were used for standardisation purposes.

Goalkeepers' external load during training movements and actions during all training and match-play sessions were monitored using a portable non differential $10-\mathrm{Hz}$ GPS integrated with a $100-\mathrm{Hz}, 3$-dimensional accelerometer, 3-dimensional gyroscope, and a 3-dimensional digital compass (STATSports Viper Pod 2, Northern Ireland) similar to GPS units used in previous investigations (Martín-García, Casamichana, Díaz, Cos, \& Gabbett, 2018). These GPS devices have shown a good level of accuracy for assessing the distance covered $(2.53 \pm 6.03 \%$ of error $)$ with accuracy improving as the distance covered increases and the speed of movements decreases (Beato, Bartolini, Ghia, \& Zamparo, 2016). In accordance with the manufacturer's recommendations, all devices were activated $15 \mathrm{~min}$ before data collection to allow acquisition of satellite signals and synchronisation of the GPS clock with the satellite's atomic clock. In order to avoid inter-unit error, each goalkeeper was assigned an individual-specific GPS device to wear during the whole observational period (Castellano, Casamichana, Calleja-González, Román, \& Ostojic, 2011). Following each training and match-play session, data were downloaded to a personal computer and analysed using a customised software package (Viper PSA software, STATSports, Belfast, Northern Ireland). External training load was assessed during training and match-play events across the following specific loading variables: Total distance covered (TD); High metabolic load distance (HMLD; distance covered when metabolic power showed a value $>25.5 \mathrm{~W} \cdot \mathrm{kg}^{-1}$ ) (Malone et al., 2018); Total high metabolic load efforts (HMLE; total count of events in which metabolic power showed a value above $25.5 \mathrm{~W} \cdot \mathrm{kg}^{-1}$ with at least $1 \mathrm{~s}$ of duration); Total high intensity $\left(>3 \mathrm{~m} \cdot \mathrm{s}^{2}\right.$ ) accelerations (ACC) and Total high intensity $\left(<-3 \mathrm{~m} \cdot \mathrm{s}^{2}\right)$ decelerations (DEC); the number of impacts $(>5 \mathrm{G})$; Dynamic stress load (DSL: total of the weighted impacts using a convex-shape function) (Malone, Mendes et al., 2018). One week before the beginning of the observational period, participants wore the GPS units within a training session in order to familiarise themselves with the research protocols. During the observational period all training and match-play sessions were completed on a natural grass surface within a pitch dimension of $\sim 100$ $\mathrm{x} 70 \mathrm{~m}$.

\subsection{Statistical analysis}

All analyses were performed using the SPSS package (v25, SPSS Inc., Chicago, USA) and data are presented as mean \pm standard deviation (SD). Initially, a Shapiro-Wilk test was used to test the normality of the data $(p>0.05)$ and all variables presented a normal distribution. To analyse the differences among the different training sessions and the match day, a one-way repeated measures analyses of variance (ANOVA) was used. In the event of a difference identified in the ANOVA, Bonferroni post hoc tests were used to identify the pairwise comparison associated to such differences. To simplify the analysis of 
data, an average of all the training sessions was used to compare the external load between starter and non-starter goalkeepers. To analyse the differences between the starter with non-starter goalkeepers, a t-test for independent samples was used. The effect size (ES) has been calculated for each pairwise comparison to the data obtained in the MD (Martín-García, Gómez Díaz, Bradley, Morera, \& Casamichana, 2018). The absolute ES value was evaluated according to the following thresholds: trivial (ES: $<0.2)$, small (ES: 0.2-0.6), moderate (ES: 0.6-1.2), large (ES: 1.2-2.0), very large (ES: 2.0-4.0) and extremely large (ES: >4.0) (Hopkins, Marshall, Batterham, \& Hanin, 2009).

\section{Results}

The mean \pm standard deviation of official soccer match-play duration was $97.5 \pm 6.7$ min with training sessions being $85.4 \pm 14.5 \mathrm{~min}$ in duration during the observational periods. Table 1 presents the specific external load data obtained for starting goalkeepers from each training and match-play session. When the external load data were analysed it was observed that TD progressively reduced from $3638 \pm 698-\mathrm{m}$ during MD-4 to $2960 \pm 516-$ $\mathrm{m}$ during MD-1 and it remained low during MD+1 (2821 $\pm 376-\mathrm{m})$. It was noted that TD values during training sessions were always observed to be lower when compared to $\mathrm{MD}$ values (5768 $\pm 776-\mathrm{m} ; p<0.05$, ES: -2.74 to -3.80 ; very large). A similar trend was observed for HMLD (246 $\pm 66-\mathrm{m}$ to $182 \pm 46-\mathrm{m}$ for MD-4 to MD-1) although only during MD-3, MD-2 and MD-1 were HMLD values lower than those reported for MD (346 $\pm 51 \mathrm{~m} ; p<0.05$, ES: -2.72 to -3.53 ; very large). When HMLE were considered these values were lower during MD-3, MD-2 and MD-1 when compared to MD values $(p<$ 0.05 , ES: -1.15 to -1.34 ; ES: moderate to large). There were no significant differences in the number of ACC and DEC although there was a tendency for a progressive reduction in these measures of the external load from MD-4 through to MD-1. In comparison to MD values, ACC and DEC were always higher in training sessions; however, this was non-significant in nature (ES: 0.19 to 2.05; small to very large) (Table 1 and Figure 1). It was observed that both impacts and DSL showed a tendency to progressive reduce from MD-4 through to MD-1 (ES: -0.69 to 0.30 ; small to moderate). Overall, MD-2 had the lowest external load consistently across the observational period.

The comparison between external load data of starting with non-starting goalkeepers are presented within Table 2. During training sessions, starting goalkeepers performed more TD ( $p<0.001$, ES: 0.36; moderate) and more HMLE $(p=0.002$, ES: 0.29 ; small) when compared to their non-starting counterparts. Across the remaining external load variables, non-significant small differences were observed between starters vs nonstarters.

\section{Discussion}

The aims of the current investigation were to quantify the external training load profile of professional soccer goalkeepers during training and match-play situations through the utilisation of GPS technology, while differentiating the external loading patterns with respect to starting and non-starting goalkeepers. The main findings of the current study indicate that during match play, goalkeepers covered more total distance (TD), high metabolic load distance (HMLD) and perform more high metabolic load efforts (HMLE) 


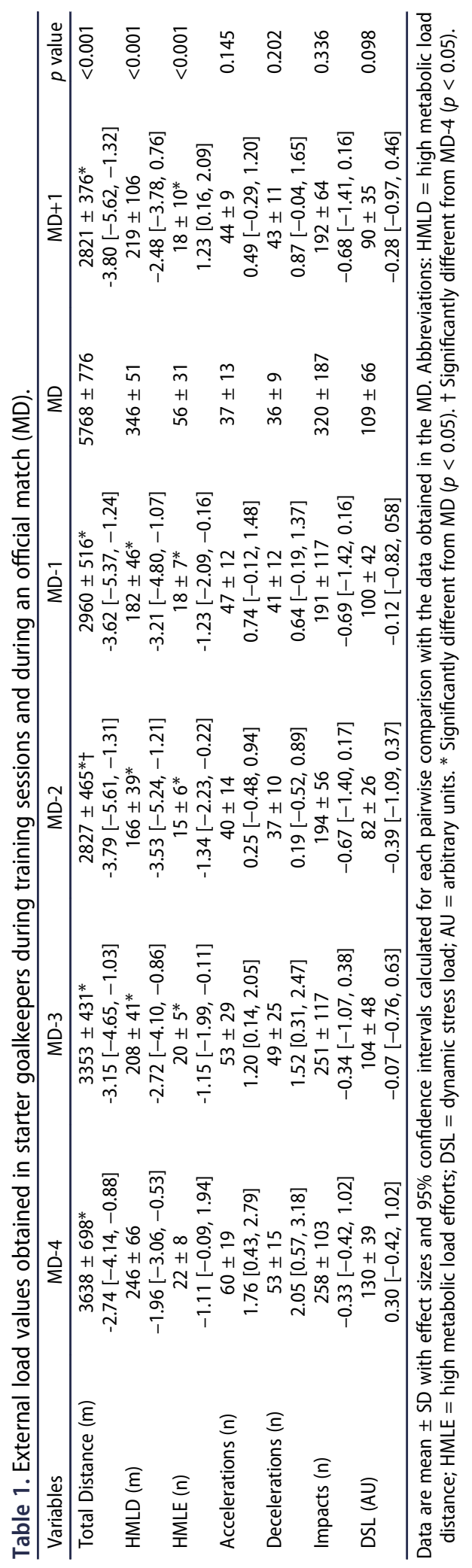




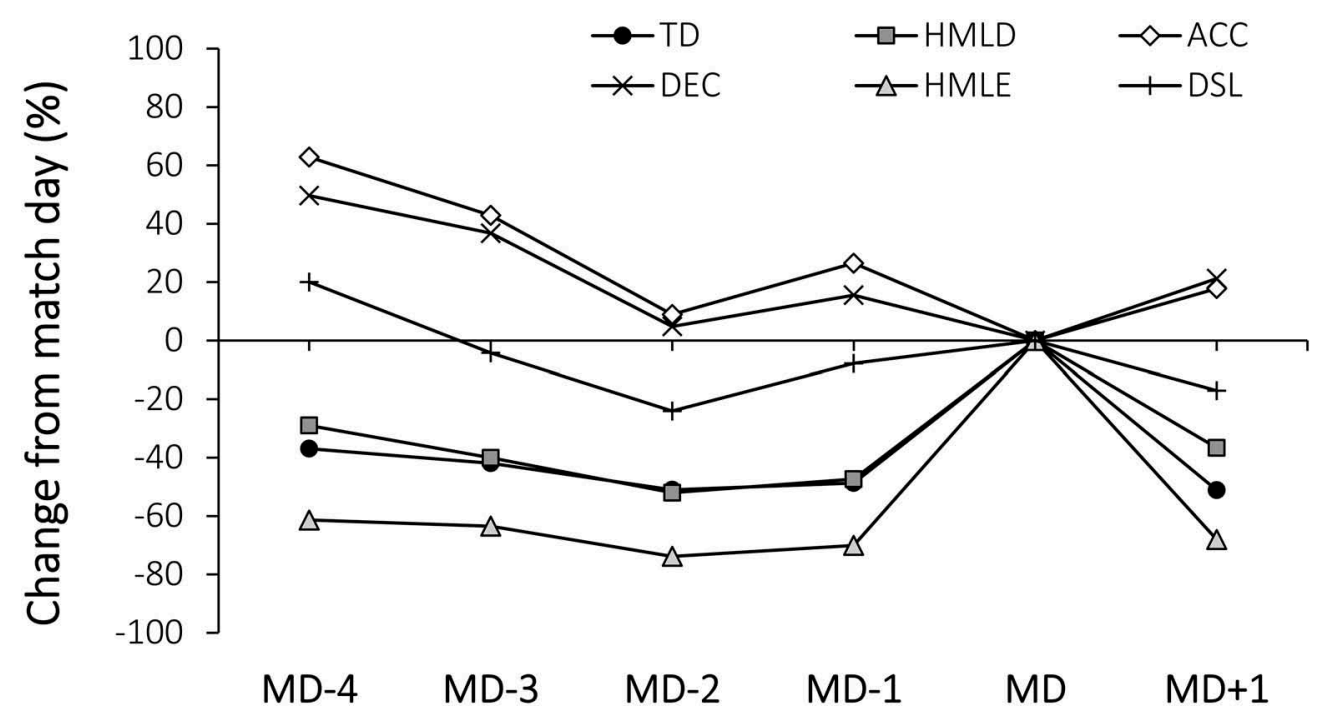

Figure 1. Evolution of the external load variables in starters goalkeepers respect from the match day.

Table 2. Comparison of external load values between starter vs non-starter goalkeepers. Data reported as mean \pm SD.

\begin{tabular}{lcccc}
\hline Variables & Starters & Non-starters & $p$ & ES [95\% Cl] \\
\hline Total Distance $(\mathrm{m})$ & $3634.39 \pm 1251.28$ & $3221.44 \pm 879.97^{*}$ & 0.001 & $0.365[0.099 \text { to } 0.631]^{*}$ \\
HMLD $(\mathrm{m})$ & $231.52 \pm 102.26$ & $206.14 \pm 110.63$ & 0.515 & $0.238[-0.008$ to 0.486$]$ \\
Accelerations $(\mathrm{n})$ & $46.48 \pm 24.26$ & $44.51 \pm 19.93$ & 0.253 & $0.087[-0.159$ to 0.334$]$ \\
Decelerations $(\mathrm{n})$ & $42.46 \pm 20.21$ & $40.02 \pm 18.47$ & 0.919 & $0.124[-0.122$ to 0.371$]$ \\
Impacts $(\mathrm{n})$ & $239.25 \pm 158.99$ & $201.8 \pm 137.99$ & 0.446 & $0.248[0.00$ to 0.496$]$ \\
HMLE (number) & $36.84 \pm 60.53$ & $22.35 \pm 26.45^{*}$ & 0.002 & $0.294[0.046 \text { to } 0.542]^{*}$ \\
DSL (AU) & $101.97 \pm 56.41$ & $104.85 \pm 51.81$ & 0.961 & $-0.052[-0.912$ to 0.627$]$ \\
\hline
\end{tabular}

Abbreviations: HMLD = high metabolic load distance; HMLE = high metabolic load efforts; DSL = dynamic stress load; $\mathrm{AU}=$ arbitrary units. ES $=$ Effect size mean [95\% confidence limits]. $\left({ }^{*}\right)$ Between-group difference $(p<0.05)$.

when compared to weekly training sessions (Figure 1). In contrast, the number of accelerations (ACC) and decelerations (DEC) during weekly training sessions were higher than those experienced during match-play. Although these differences were not significant in nature, overall it appears from the analysis that all external load variables were progressively reduced from MD-4 to MD-1 to accommodate improved physical condition and recovery to ensure maximal performance by players during competition. Furthermore, we observed that starting goalkeepers showed increased external loads for TD and HMLE values compared to non-starting goalkeepers. The information presented within the current investigation might be valuable to coaches in order to improve the prescription of training loads in order to best replicate the competition demands of soccer goalkeepers. The data suggest the need to develop training drills that increase the volume of running distance and high metabolic load efforts while reducing in the number and frequency of accelerations and decelerations.

We observed that TD covered for professional soccer goalkeepers ranges between $2821 \pm 376-\mathrm{m}$ to $3638 \pm 698-\mathrm{m}$ during the week of competition. Interestingly, these distances covered during training are well below those obtained during the match 
$(5768 \pm 776-\mathrm{m})$. These results are in agreement with the findings of previous studies that analysed the TD covered by goalkeepers during training (Malone, Jaspers et al., 2018) and match-play (Di Salvo et al., 2008). A similar trend was observed across the distance and actions performed above $25 \mathrm{~W} \cdot \mathrm{kg}^{-1}$, a threshold previously suggested to discriminate those actions that require high values of metabolic power (Malone, Mendes, et al., 2018). By using a within-subjects analysis, it can be suggested that, during training sessions, the total distance covered, distance and number of efforts performed at high metabolic power were not in-line with the typical external load experienced by soccer goalkeepers during official soccer matchplay. Indeed, the observed elevated external load in MD session for the above variables may be related to the high-intensity actions performed at high displacement and duration during match-play actions (Martín-García et al., 2018) that are not regularly replicated during training sessions. Thus, the development and utilisation of goalkeeping drills that increase total running volume while also maintaining the technical and tactical elements of goalkeeping might be recommended to reduce the apparent observed disparity between training and competition demands within the current investigation.

During the investigation, we observed that the external load from MD-4 training sessions were progressively reduced through to MD-1 sessions (Martín-García, Gómez Díaz, et al., 2018), although, overall, MD-2 had the lowest external load values (Table 1). According to Martín-García, Gómez Díaz, et al., 2018, soccer coaches are agile with respect to their training periodisation and have been noted to consistently adjust planned external load in accordance with the physical status of players across playing minutes, recovery status, wellness status, and conditioning requirements. Within our investigation, we show support for this narrative by reporting a progressive pattern of load reduction during the microcycle prior to match-play. Despite, the differences in the competitive standards of players and the training methodologies, analysis of the loading patterns imposed during training session indicated that MD-4 represents the highest external load during the weekly training period and an apparent aim by coaches to evoke training adaptations through intense actions during MD-4. The remaining training sessions appear to be focused towards balancing the fitness-fatigue paradigm with steady reductions in external load towards match-play while $\mathrm{MD}+1$ was consistently shown to be focused towards active recovery.

Another interesting finding within the investigation was that the number of ACC and DEC during the training sessions prior to match-play tended to be higher than the number of ACC and DEC efforts produced by soccer goalkeepers during matchplay. These findings may suggest an increased mechanical workload for goalkeepers during training situations when compared to match-play. The findings may be explained by a position-specific focus of the goalkeeper training within the teams analysed, where goalkeepers completed exercises that typically involved ACC and DEC actions such as dives, saves, clearances, slide-tackles in addition to acceleration efforts to close down oncoming opposition players. In fact, our data indicate that the number of these high-accelerative actions exceeds the values found typically during official competition. This difference may be interpreted as positive as exposure to these movements may improve the quality of these actions. However, practitioners must also consider the increased metabolic and mechanical loading that ACC and 
DEC efforts impose on the physiological systems of players, additionally increased high loading exposure to these efforts may represent an injury risk if not managed appropriately over time (Figure 1).

When we analysed the different external load profiles of starting vs non-starting goalkeepers, it was observed that starting goalkeepers presented greater external loads for TD and HMLE when contrast against non-starting goalkeepers (Table 2). The current data appear to be the first communicated within the literature. However, the present outcomes appear to be in line with previous studies conducted within outfield players (Anderson et al., 2016) and might indicate that starting players are subjected to higher physical demands during training. These increased training demands in conjunction with match-play load may predispose them to increased physical conditioning when compared to non-starters. Reductions in running actions, especially the ones performed at high intensity and metabolic power seem to be related to a lower time participation in drills and match-play during microcycle for non-starting goalkeepers which may reduce their physical, technical and tactical training adaptation in comparison to starting goalkeepers. The above finding is one that should be brought into sharp focus for practitioners and coaches alike, there would appear to be a need to assure that additional workloads be prescribed in the correct manner for non-starting goalkeepers to ensure technical and tactical exposure is prescribed to minimise the reduction in exposure when compared to starting goalkeepers. Therefore, there should be a concerted effort made during the training sessions, to expose both starting and non-starting goalkeepers to similar loads, with additional load prescribed for non-starting keepers to ensure similar levels of physical conditioning for match-play.

While the results of this study provide new information regarding the quantification of external imposed on soccer goalkeepers during a structured microcycle, these findings must be considered with respect to a number of limitations. Firstly, as the current study has been performed in a small sample of professional goalkeeper soccer players (20 players), these findings may not be extended to another populations. Additional potential weakness is that the current information is related to the one moment of the season (microcycle) and do not provide information on how these values may vary during the season (macrocycle). Despite these limitations, the current investigation shows for the first time how goalkeepers external load fluctuates during a microcycle and evidences the differences in the physical challenges imposed by training vs official match competition.

\section{Practical applications}

Training specificity is important for stimulating training adaptations to improve performance. Understanding the training and competition demands of a sport is therefore of paramount importance for strength and conditioning coaches in order to ensure the appropriate dose is planned to maximise the fitness-fatigue response within athletes. Despite this, few data are currently available on the external training and match-play demands of elite level goalkeepers within soccer. To provide relevant up to date data on training and match-play demands the current study examined the training and match the performance of elite goalkeepers. The main findings of the current study indicate that during match play, goalkeepers covered more total distance (TD), distance at high 
metabolic load (HMLD) and perform more efforts at high metabolic load (HMLE) when compared to training sessions. In contrast, the number of accelerations (ACC) and decelerations (DEC) during the training sessions was higher than those experienced during match-play. Overall, all external load variables were progressively reduced from MD-4 to MD-1 representative of appropriate strategies to ensure maximal recovery for the challenges of the competition. Furthermore, starting goalkeepers covered greater TD and HMLE when compared to non-starters goalkeepers. Analysis of the findings highlights the need for position-specific physical conditioning drills that replicate the performance needs of professional goalkeepers, for example, the utilisation of drills that increase running distances and actions at high metabolic loads while reducing the frequency acceleration and deceleration efforts. Overall coaches should consider the positional demands of goalkeepers and the differing performance needs of staters and non-starters to better optimise training outcomes for these players.

\section{Conclusions}

In conclusion, the results of this study reveal that running actions, especially the ones performed at high metabolic load, were higher during match-play when compared to training sessions. On the contrary, there appears to be an over-exposure to accelerations and decelerations during training sessions when compared to the demands of match-play. Although the external load during the microcycle that precedes an official match is progressively reduced, it might be suggested that the use of training routines that increase running distance and actions at high metabolic loads with a reduction in the exposure to accelerations and decelerations might be more suitable to accommodate the specific demands of professional goalkeepers during the game. We finally suggest that non-starter goalkeepers are exposed to top-up physical, technical and tactical loading order to reduce the disparity between starter and non-starter goalkeepers within the current investigation. All this information could be useful for coaches when trying to systematically manage load in goalkeepers.

\section{Acknowledgments}

The authors wish to thank the participants and coaches for their invaluable contribution to the study.

\section{Disclosure statement}

No potential conflict of interest was reported by the authors.

\section{ORCID}

Victor Moreno-Pérez (D) http://orcid.org/0000-0003-3357-0045

\section{References}

Anderson, L., Orme, P., Di Michele, R., Close, G. L., Milsom, J., Morgans, R., .. Morton, J. P. (2016). Quantification of seasonal-long physical load in soccer players with different starting 
status from the english premier league: Implications for maintaining squad physical fitness. International Journal of Sports Physiology and Performance, 11(8), 1038-1046.

Bangsbo, J., Mohr, M., \& Krustrup, P. (2006). Physical and metabolic demands of training and match-play in the elite football player. Journal of Sports Sciences, 24(7), 665-674.

Barberó-Âlvarez, J. C., Boullosa, D., Nakamura, F. Y., Andrín, G., \& Weston, M. (2014). Repeated Acceleration Ability (RAA): A new concept with reference to top-level field and assistant soccer referees. Asian Journal of Sports Medicine, 5(1), 63-66. Retrieved from http://www.ncbi.nlm. nih.gov/pubmed/24868433

Beato, M., Bartolini, D., Ghia, G., \& Zamparo, P. (2016). Accuracy of a $10 \mathrm{~Hz}$ GPS unit in measuring shuttle velocity performed at different speeds and distances (5-20 M). Journal of Human Kinetics, 54(1), 15-22.

Brink, M. S., Nederhof, E., Visscher, C., Schmikli, S. L., \& Lemmink, K. A. P. M. (2010). Monitoring load, recovery, and performance in young elite soccer players. Journal of Strength and Conditioning Research, 24(3), 597-603.

Castellano, J., Casamichana, D., Calleja-González, J., Román, J. S., \& Ostojic, S. M. (2011). Reliability and accuracy of $10 \mathrm{~Hz}$ GPS devices for short-distance exercise. Journal of Sports Science \& Medicine, 10(1), 233-234. Retrieved from http://www.ncbi.nlm.nih.gov/pubmed/24137056

Di Salvo, V., Benito, P. J., Calderón, F. J., Di Salvo, M., \& Pigozzi, F. (2008). Activity profile of elite goalkeepers during football match-play. The Journal of Sports Medicine and Physical Fitness, 48 (4), 443-446. Retrieved from http://www.ncbi.nlm.nih.gov/pubmed/18997646

Drew, M. K., \& Finch, C. F. (2016). The relationship between training load and injury, illness and soreness: A systematic and literature review. Sports Medicine (Auckland, N.Z.), 46(6), 861-883.

Gabbett, T. J., Kennelly, S., Sheehan, J., Hawkins, R., Milsom, J., King, E., ... Ekstrand, J. (2016). If overuse injury is a "training load error", should undertraining be viewed the same way? British Journal of Sports Medicine, 50(17), 1017-1018.

Gabbett, T. J., \& Whiteley, R. (2017). Two training-load paradoxes: Can we work harder and smarter, can physical preparation and medical be teammates? International Journal of Sports Physiology and Performance, 12(s2), S2-50-S2-54.

Hopkins, W. G., Marshall, S. W., Batterham, A. M., \& HANIN, J. (2009). Progressive statistics for studies in sports medicine and exercise science. Medicine \& Science in Sports \& Exercise, 41(1), 3-13.

Iaia, F. M., Rampinini, E., \& Bangsbo, J. (2009). High-intensity training in football. International Journal of Sports Physiology and Performance, 4(3), 291-306. Retrieved from http://www.ncbi. nlm.nih.gov/pubmed/19953818

Krustrup, P., Helsen, W., Randers, M. B., Christensen, J. F., MacDonald, C., Rebelo, A. N., \& Bangsbo, J. (2009). Activity profile and physical demands of football referees and assistant referees in international games. Journal of Sports Sciences, 27(11), 1167-1176.

Liu, H., Gómez, M. A., \& Lago-Peñas, C. (2015). Match performance profiles of goalkeepers of elite football teams. International Journal of Sports Science and Coaching, 10(4), 669-682.

Lopes, J. E., Araújo, D., Duarte, R., Davids, K., \& Fernandes, O. (2012). Instructional constraints on movement and performance of players in the penalty kick. International Journal of Performance Analysis in Sport, 12(2), 311-345.

Malone, J. J., Jaspers, A., Helsen, W., Merks, B., Frencken, W. G. P., \& Brink, M. S. (2018). Seasonal training load and wellness monitoring in a professional soccer goalkeeper. International Journal of Sports Physiology and Performance, 13(5), 672-675.

Malone, S., Mendes, B., Hughes, B., Roe, M., Devenney, S., Collins, K., \& Owen, A. (2018). Decrements in neuromuscular performance and increases in creatine kinase impact training outputs in elite soccer players. Journal of Strength and Conditioning Research, 32(5), 1342-1351.

Martín-García, A., Casamichana, D., Díaz, A. G., Cos, F., \& Gabbett, T. J. (2018). Positional differences in the most demanding passages of play in football competition. Journal of Sports Science \& Medicine, 17(4), 563-570. Retrieved from http://www.ncbi.nlm.nih.gov/pubmed/30479524

Martín-García, A., Gómez Díaz, A., Bradley, P. S., Morera, F., \& Casamichana, D. (2018). Quantification of a professional football team's external load using a microcycle structure. Journal of Strength and Conditioning Research, 32(12), 3511-3518. 
Mohr, M., Krustrup, P., \& Bangsbo, J. (2003). Match performance of high-standard soccer players with special reference to development of fatigue. Journal of Sports Sciences, 21(7), 519-528.

Osgnachsgnach, C., Poser, S., Bernardini, R., Rinaldo, R., \& Di Prampero, P. E. (2010). Energy cost and metabolic power in elite soccer. Medicine \& Science in Sports \& Exercise, 42(1), 170-178.

Polglaze, T., \& Hoppe, M. W. (2019). Metabolic power: A step in the right direction for team sports. International Journal of Sports Physiology and Performance, 14(3), 407-411.

Russell, M., Rees, G., Benton, D., \& Kingsley, M. (2011). An exercise protocol that replicates soccer match-play. International Journal of Sports Medicine, 32(7), 511-518.

Seaton, M., \& Campos, J. (2011). Distribution competence of a football clubs goalkeepers. International Journal of Performance Analysis in Sport, 11(2), 314-324.

Weston, M., Castagna, C., Helsen, W., \& Impellizzeri, F. (2009). Relationships among field-test measures and physical match performance in elite-standard soccer referees. Journal of Sports Sciences, 27(11), 1177-1184.

White, A., Hills, S. P., Cooke, C. B., Batten, T., Kilduff, L. P., Cook, C. J., ... Russell, M. (2018). Match-play and performance test responses of soccer goalkeepers: A review of current literature. Sports Medicine (Auckland, N.Z.), 48(11), 2497-2516.

Ziv, G., \& Lidor, R. (2011). Physical characteristics, physiological attributes, and on-field performances of soccer goalkeepers. International Journal of Sports Physiology and Performance, 6(4), 509-524. Retrieved from http://www.ncbi.nlm.nih.gov/pubmed/22248551 